\title{
Efficacy of azithromycin versus other antibiotics in the treatment of patients with upper respiratory tract infections
}

\author{
Lyna Lima ${ }^{1 *}$, José Antonio Pinto ${ }^{2}$, Heloisa Nunes ${ }^{3}$, Pedro Paulo V. C. Cintra ${ }^{3}$, Cassia Onofre ${ }^{1}$, Pedro Gregório M Filho ${ }^{1}$, Caio Alonso ${ }^{1}$ and \\ Roberta Moss Rinke ${ }^{1}$ \\ ${ }^{1}$ Physicians in the Otorhinolaryngology Department of the Nucleus for Otorhinolaryngology, Head and Neck Surgery and Sleep Medicine, Brazil \\ ${ }^{2}$ Director of the Nucleus for Otorhinolaryngology, Head and Neck Surgery and Sleep Medicine, Brazil \\ ${ }^{3}$ Assistant Physician at the Nucleus for Otorhinolaryngology, Head and Neck Surgery and Sleep Medicine, Brazil
}

\begin{abstract}
Introduction: upper respiratory tract infections (URTI) are one of the most common problems found in medical care services, especially in the pediatric population. Among the infectious pathologies of the upper respiratory tract, we include acute sinusitis, acute otitis media, pharyngitis, tonsillitis. Of the therapies adopted, we have the indication of prescription penicillins, cephalosporins, macrolides, aminoglycosides, quinolones and tetracyclines as an option for the treatment of URTI with the indication of the first antimicrobial choice varying according to the established etiology. However, in clinical practice, there is increasing resistance in certain initial antimicrobial therapies (mainly amoxicillin and azithromycin) and, therefore, studies for better investigation become more frequent.
\end{abstract}

Objective: to evidence and to verify the resistance and increasing ineffectiveness of certain initial antibiotic therapies in the treatment of URTI.

Methods: In order to carry out this study, data were collected from patients seen in a specialized emergency room with a clinical history of URTI and failure of first choice antimicrobial therapy from 2018 to 2020 under an established criterion;

Results: there was a considerable prevalence of patients with refractory URI who used azithromycin (44\%) alone and amoxicillin (15\%), mainly.

Conclusion: We have confirmed the ineffectiveness of using azithromycin as the first choice for the treatment of URTI.

\section{Introduction}

Upper respiratory tract infections (URTIs) are one of the most common problems found in pediatric emergency care services, resulting in significant morbidity worldwide. URTIs are the most common cause of children treated for acute respiratory infection. The difficulties observed in clinical practice in relation to the differential and etiological diagnosis of certain URTIs and the use, often abusive, of antimicrobials [1]. In addition, they are a very frequent cause of recourse to Primary Health Care (PHC), with a frequency of 11 to $33 \%$ of URTIs being reported in all reasons for consulting General and Family Medicine [2].

The most common URTIs are acute sinusitis, acute otitis media, pharyngitis, tonsillitis, among other pathologies.

It is known that the nasal epithelium is the main portal of entry for respiratory viruses, as well as an active component of the host's initial responses against viral infection. The inflammation cascade initiated by nasal epithelial cells will lead to damage by infiltrating cells, causing edema, engorgement, fluid leakage, mucus production and sinus obstruction in the process, leading to acute rhinosinusitis (ARS) [3].

Most ARS are self-limiting and can be classified as a common cold. Common colds are defined as acute viral rhinosinusitis with symptom duration $<10$ days (but less than 12 weeks). When symptoms increase after five days or when symptoms persist for more than 10 days, less than 12 weeks in duration, it is classified as acute post-viral rhinosinusitis.
Only a minority of acute rhinosinusitis is of acute bacterial origin and is defined when the patient has at least three of the five symptoms/ signs: 1) Discolored mucus, 2) severe local pain (usually unilateral), 3) Fever $\left.>38^{\circ} \mathrm{C}\left(100.4^{\circ} \mathrm{F}\right) 4\right)$ high ESR and 5) double" sicking [3].

According to Scheid and Hamm, although most cases of acute rhinosinusitis are caused by viruses, acute bacterial rhinosinusitis is a very common complication and most patients with acute rhinosinusitis recover quickly without antibiotic therapy, although it should be considered in patients with prolonged or more severe symptoms, such as high fever $\left(>39^{\circ} \mathrm{C}\right.$ or $\left.102.2^{\circ} \mathrm{F}\right)$ or persistent fever, periorbital swelling, severe facial or dental pain, altered mental status, diplopia and infraorbital hypesthesia [4].

Among the therapies adopted for URTIs we have as indication the prescription penicillins, cephalosporins, macrolides, aminoglycosides, quinolones and tetracyclines as an option [5-7].

However, the first three groups of antimicrobials mentioned end up being the most used ones in daily life, especially penicillins, with

${ }^{\star}$ Correspondence to: Lyna Lima, Department of Otolaryngology, Center for Otorhinolaryngology and Head and Neck Surgery of São Paulo, Brazil; E-mail: lyna.lima88@gmail.com

Key words: azithromycin, upper respiratory tract infections

Received: January 25, 2021; Accepted: February 19, 2021; Published: February 26,2021 
amoxicillin as the main representative or not associated with potassium clavulanate, and macrolides, which most often have azithromycin as their representative as antimicrobial therapy. Nevertheless, in clinical practice, a certain resistance is observed in the therapies used to the first choice antimicrobials [5-7].

Pharyngotonsillitis (PT), self-limiting infections that develop in the tonsils, posterior pharynx, soft palate, lymphoid organs, represent one of the most frequent infections of the upper respiratory tract, especially in the child population, with symptoms such as fever, exudate in the pharynx and tonsils with hyperemia, myalgia, among other symptoms that, if not treated properly, can lead to systemic complications in the patient, including rheumatic fever and glomerulonephritis.

Thus, one should start with correct antibiotic therapy as soon as possible, which quickly suppresses the infection. Among them we have Penicillin as the antibiotic of choice, and Amoxicillin, Ampicillin, Macrolides (for patients allergic to Penicillin) and even cephalosporins. Relapse cases are usually due to the presence of betalactamase-producing copathogens; for these, Amoxicillin associated with Clavulanic Acid has been shown to be efficient, as well as Cephalosporins and Macrolides or Clindamycin [8].

In the case of acute otitis media (AOMs), they are defined as the rapid onset of signs and symptoms of inflammation of the mucoperiosteum of the middle ear of viral or bacterial origin. Epidemiological evidence shows that AOM is often also a consequence of URTI, in which viruses would act as copathogens, predisposing to bacterial infection. The clinical frame is characterized by otalgia, fever, irritability, decreased appetite, vomiting, diarrhea. The finding with the greatest prognostic power for AOM is the bulging of the tympanic membrane [9].

Therefore, Amoxicillin is recommended as the treatment of choice in AOM, Sulfamethoxazole-Trimethoprim (SMZ-TMP), Azithromycin or Clarithromycin are drugs that do not have good coverage for $H$. influenzae and SMZTMP for resistant S. pneumoniae [9].

In acute sinusitis, an estimated 20 million cases occur annually in the United States. According to data from the National Ambulatory Medical Care Survey (NAMCS), sinusitis is the fifth most common diagnosis for which an antibiotic is prescribed and the increasing prevalence of non-susceptibility to penicillin and resistance to other classes of drugs among $S$. pneumoniae has been a problem in the United States, with 15\% intermediate to penicillin and 25\% resistant to penicillin in recent studies. Resistance to macrolides and trimethoprim/ sulfamethoxazole (TMP/SMX) is also common in S. pneumoniae [10].

In general, the guidelines recommend first-line antibiotic therapy for each condition: amoxicillin or amoxicillin with clavulanate (alternative) for AOM, amoxicillin or amoxicillin with clavulanate for sinusitis and penicillin or amoxicillin for pharyngitis. First-line therapy represents the initial antibiotics recommended for the treatment of patients without drug allergies, and the most common class of nonfirst-line antibiotics prescribed was macrolides [11].

\section{Objective}

The aim of the present study is to highlight and verify the increasing resistance and ineffectiveness of certain first-line antibiotic therapies for the treatment of bacterial origin upper airway infections in the adult and child population, considering that this phenomenon can increasingly be observed in the routine of outpatient clinics, emergency care and otorhinolaryngology emergency room.

\section{Methods}

Data were collected from 71 patients, including men and women, aged between 0 and 80 years, which were acquired in the field, in an outpatient clinic and emergency care in Otorhinolaryngology, from January 2019 to February 2020, where patients reported antibiotic use and returned due to no improvement in the clinical frame.

We conducted a questionnaire to find out which medicine was used, for how long and for what pathology. The questionnaire data was always collected by the same doctors, in a standardized manner.

\section{Results}

After collecting the data and analyzing the questionnaires, we observed that in most services, the antibiotics used are almost entirely oral and injectable penicillins and macrolides.

Only 7.2\% of the patients used antibiotics from other classes, other than penicillins or macrolides, and did not obtain a positive result, having to exchange the antibiotic to stop the present infection, as we can see in Graph 1 . We can point out that only $10 \%$ of patients who had maintained the disease had used the combination of Amoxicillin with Clavulanic acid.

The antibiotic with the highest rate of ineffectiveness, making the patient return to medical service was Azithromycin, as shown in Graph 1.

Among the most treated pathologies during this study, we have, among others, tonsillitis, acute otitis media and acute sinusitis. According to Graph 2, there is a higher prevalence of tonsillitis (37 patients $-52.9 \%)$ in patients seeking medical care, followed by sinusitis (18 patients - 25.7\%), AOMs (12 patients - 17, 15\%)) and others (3 patients $-4.25 \%)$.

In addition, the average age of the patients was 29.95 years, with greater demand from female patients, with 38 cases $(53.5 \%)$ and male patients with 33 cases (46.5\%).

We also observed, according to graphs 3,4 and 5 that the prevalence of Azithromycin in the prescription of the three main pathologies present in the study, is always greater than the prescription of other antibiotics, being prescribed in $42 \%$ in the uncured AOMs, $40 \%$ in acute tonsillitis and $59 \%$ in acute sinusitis.

Only 2 patients (2.85\%) evolved with complications of the underlying disease. Both patients had acute tonsillitis, evolving with peritonsillar abscess. One using Clarithromycin, the other using Benzetacil.

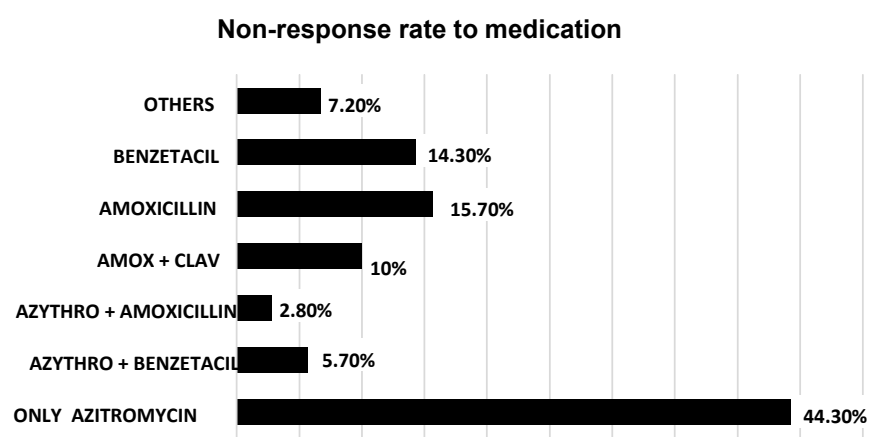

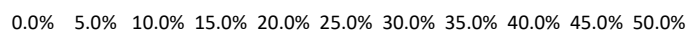

Graph 1. Rate of non-response to the antibiotic prescribed at the first consultation, making the patient return in order to change medication 
The average, in days, of patients' return to the clinic was 5 days.

\section{Discussion}

Acute respiratory infections can be classified according to their anatomical location as: upper respiratory tract infections, which include rhinopharyngitis, pharyngitis and tonsillitis, otitis media, sinusitis and laryngitis [10].

Inappropriate prescribing of antibiotics also includes choosing an unnecessarily broad spectrum antibiotic, rather than a narrower, equally or more effective alternative. Otitis media (OM), sinusitis

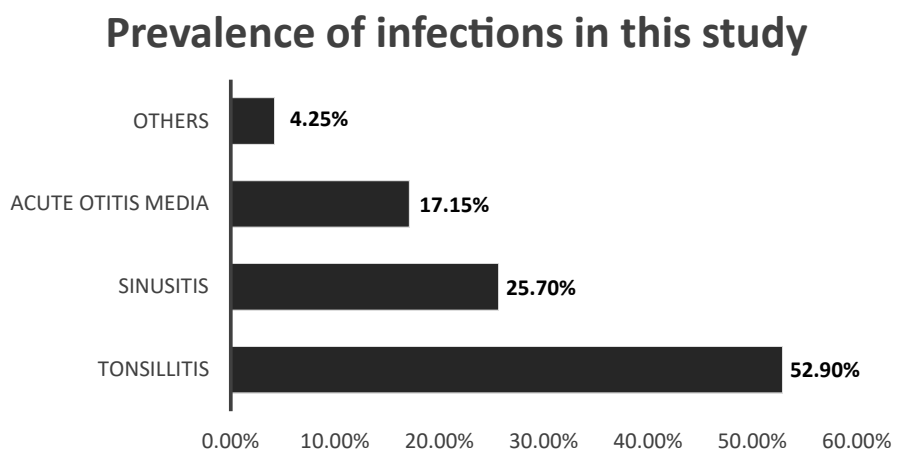

Graph 2. Rate of the most prevalent pathologies in this study

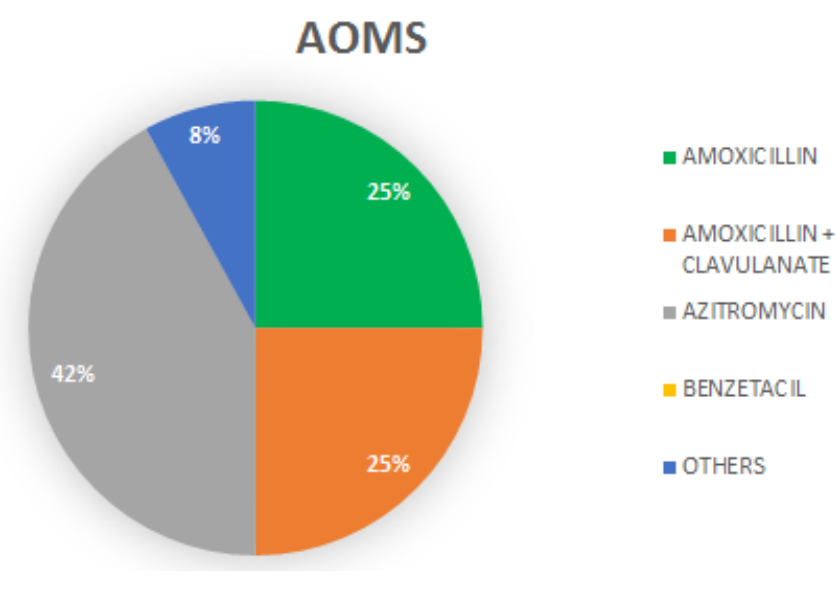

Graph 3. Prevalence rate of the most used antibiotics in the case of AOMs

\section{ACUTE TONSILLITIS}

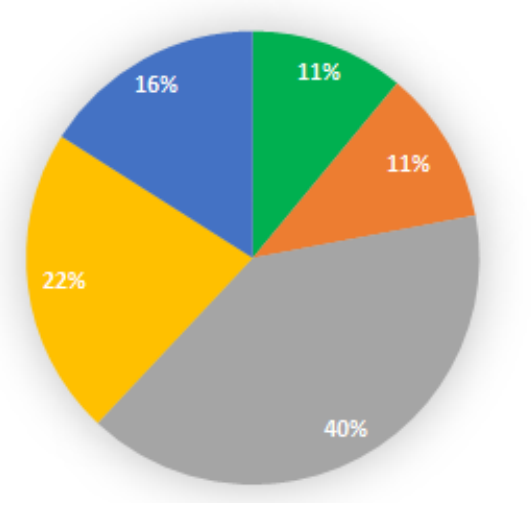

- AMOXICILLIN

- AMOXICILLIN + CLAVULANATE

aZITROMYCIN

- BENZETACIL

- OTHERS

Graph 4. Prevalence rate of the most used antibiotics in case of acute tonsillitis

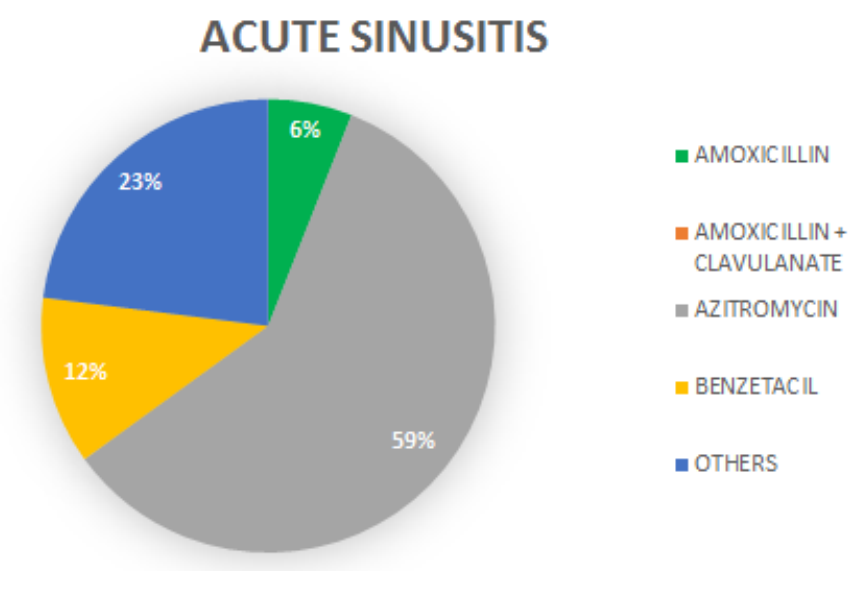

Graph 5. Prevalence rate of the most used antibiotics in case of acute sinusitis

and pharyngitis collectively represent almost a third of all antibiotics prescribed in an outpatient setting [11].

Macrolid antibiotics are commonly used to treat respiratory tract infections. Three of the most used agents in this class are azithromycin, clarithromycin and erythromycin. However, as with other antibiotics, there is a growing global concern about the progressive development of bacterial resistance to these agents. The rate of resistance to macrolides in Streptococcus pneumoniae has been reported to vary from 4 to $70 \%$ in surveillance studies worldwide, the most important factor in the development of antimicrobial resistance in S. pneumoniae and other bacteria being the inappropriate and widespread use. of antibiotics [13]. According to Hoban and Zhanel, clarithromycin and azithromycin are advanced macrolides that concentrate extensively on respiratory tissues and have anti-inflammatory properties that increase efficacy, however Clarithromycin has a potency 40 times greater than Azithromycin against pneumococci, suggesting clinical efficacy against resistance [14,15].

According to Frost, McLean and Chow, electronic medical records from 2011 to 2016 were extracted for the diagnosis of upper respiratory infection, pharyngitis, acute otitis media and sinusitis and antibiotics were found to be the most commonly prescribed drugs for children in the USA, accounting for 68 million prescriptions annually [16].

It is estimated that $30 \%$ to $50 \%$ of outpatient antibiotic prescriptions in the USA are not necessary. Excessive use of antibiotics has resulted in an alarming increase in antibiotic resistance [16].

The same example was confirmed in the study by Frost, McLean and Chow, in which the rate of resistance to macrolides among Streptococcus pneumoniae, a primary cause of acute otitis media (AOM), sinusitis and community-acquired pneumonia in children, increased by $18 \%$ in 1998 to $35 \%$ in 2015 [16].

The same was observed in this study, that the majority of patients who returned for medical care had used Azithromycin to treat the underlying pathology, which was prescribed, at approximately the same frequency for the three main diseases (acute tonsillitis, acute sinusitis and $\mathrm{AOMs}$ ).

It is known that the first-line treatment for the treatment of OMAa, acute sinusitis and acute tonsillitis, are penicillins, which when prescribed for oral presentation on an outpatient basis, are represented by Amoxicillin or Amoxixilina associated with clavulanic acid (in cases of recent use in time) less than 30 days) [16-18]. 
In this study, the improvement in its effectiveness was confirmed, in face of the use of macrolides, mainly Azithromycin, which is still the representative of the most used class in our country. It was proven in this study that $44.3 \%$ of the patients who used Azithromycin had to return to the office in 5 days to change the antibiotic. This is not in agreement with a study by Dunne et al., which reports that Azithromycin administered for three days is as effective as Amoxicillin with Clavulanic Acid in the treatment of AOM and may result in a more complete resolution of tympanic membrane disease and is better tolerated [19]. The study by Dunne et al. was carried out in 2003, which may suggest that at that time bacterial resistance to Azithromycin was not as current as it is today.

Several studies in the literature also address the comparison of Azithromycin x Amoxicillin (or Amoxicillin + Clavulanic acid) in view of better adherence to treatment, since the long half-life of Azithromycin allows oral therapy in a single dose, for example, for acute otitis media (AOM), while Amoxicillin requires at least two daily doses [19]. This comparison was not possible to be carried out in our study, as there were patients who came with the proposed treatment from another service, and it was not possible to make an initial investigation as to the patient's preference. However, the higher rate of patients who returned for not exterminating the disease used Azithromycin, which may infer a choice, from the patient or the doctor for a single dose medication.

Morris et al. also mentioned the same comparison in their study, which showed that, in the treatment of AOMs, Azithromycin in a single dose did not reduce (or increase) the risk of clinical failure compared with Amoxicillin (2 doses a day) and clinical failure was high in both treatment groups [21]; as well as Acerbi et al. and Arguedas et al., in their studies, Azithromycin in a single dose was also as effective as a high dose of amoxicillin for the treatment of children with AOM [21,22].

These studies differ from our research, which demonstrated greater clinical failure with Azithromycin [22,23].

\section{Conclusion}

Although the spectrum of pathogens varies with age, in this study they were not differentiated, which may be studied in a future study. The study confirms the ineffectiveness in the use of Azithromycin, nowadays, in order to treat the main infections of the upper airways, in face of the use of antimicrobials considered first-line at the moment.

\section{References}

1. Pitrez Paul MC, Pitrez José LB (2003) Acute upper respiratory tract infections: outpatient diagnosis and treatment. J Pediatr 79: S77-S86. [Crossref]

2. Monteiro AB, Castanheira AD, Castro M, Capela N (2011) Perfil de prescrição antibiótica no tratamento das Infecções das Vias Aéreas Superiores. Revista Portuguesa de Clínica Geral 27: 502-506.

3. Rinossinusite aguda incluindo resfriado comum e RSAR em adultos e crianças (2020) European Position Paper on Rhinosinusitis and Nasal Polyps 53-95.

4. Scheid DC, Hamm RM (2004) Acute bacterial rhinosinusitis in adults: part II. Treatment. Am Fam Physician 70: 1697-1704. [Crossref]
5. NIEMLA M, et al. (2000) Literature Reviews: Pediatric Infectious Diseases, Clin Pediatrics 106: 483-488,

6. Bachert C, Hörmann K, Mösges R, Rasp G, Riechelmann H, et al. (2003) An update on the diagnosis and treatment of sinusitis and nasal polyposis. Allergy 58: 176-191. [Crossref]

7. Cars O, Mölstad S, Melander A (2001) Variation in antibiotic use in the European Union. Lancet 357: 1851-1853. [Crossref]

8. Choby BA (2009) Diagnosis and treatment of streptococcal pharyngitis. Am Fam Physician 79: 383-390. [Crossref]

9. American Academy of Pediatrics Subcommittee on Management of Acute Otitis Media (2004) Diagnosis and management of acute otitis media. Pediatrics 113: 1451-1465. [Crossref]

10. Universidade Aberta do SUS - UNASUS (2012) Fundamentação teórica - Infecções respiratórias agudas - Especialização em SAÚDE DA FAMÍLIA

11. Hersh AL, Fleming-Dutra KE, Shapiro DJ, Hyun DY, Hicks LA (2016) Outpatient Antibiotic Use Target-Setting Workgroup. Frequency of First-line Antibiotic Selection Among US Ambulatory Care Visits for Otitis Media, Sinusitis, and Pharyngitis. JAMA Intern Med 176: 1870-1872. [Crossref]

12. Anon JB, Jacobs MR, Poole MD, Ambrose PG, Benninger MS, et al. (2004) Sinus And Allergy Health Partnership. Antimicrobial treatment guidelines for acute bacterial rhinosinusitis. Otolaryngol Head Neck Surg 130: 1-45. [Crossref]

13. Halpern MT, Schmier JK, Snyder LM, Asche C, Sarocco PW, et al. (2005) Meta-analysis of bacterial resistance to macrolides. J Antimicrob Chemother 55: 748-757. [Crossref]

14. Hoban DJ, Zhanel GG (2006) Clinical implications of macrolide resistance in community-acquired respiratory tract infections. Expert Rev Anti Infect Ther 4: 973980. [Crossref]

15. Karlowsky JA, Lagacé-Wiens PR, Low DE, Zhanel GG (2009) Annual macrolide prescription rates and the emergence of macrolide resistance among Streptococcus pneumoniae in Canada from 1995 to 2005. Int J Antimicrob Agents 34: 375-379. [Crossref]

16. Frost HM, McLean HQ, Chow BDW (2018) Variability in Antibiotic Prescribing for Upper Respiratory Illnesses by Provider Specialty. J Pediatr 203: 76-85. [Crossref]

17. Cohen R (2004) Defining the optimum treatment regimen for azithromycin in acute tonsillopharyngitis. Pediatr Infect Dis J 23: S129-134. [Crossref]

18. Grasel SS, Francesco RC, Beck RMO, Almeida ER (2017) Faringotonsilites e Hipertrofia das Tonsilas Palatinas e Faríngea, Tratado de otorrinolaringologia e Cirurgia Cérvicofacial da ABORL-CCF.

19. Dunne MW, Latiolais T, Lewis B, Pistorius B, Bottenfield G, et al. (2003) Randomized, double-blind study of the clinical efficacy of 3 days of azithromycin compared with co-amoxiclav for the treatment of acute otitis media. J Antimicrob Chemother 52: 469472. [Crossref]

20. Block SL, Arrieta A, Seibel M, McLinn S, Eppes S, et al. (2003) Single-dose (30 mg/ $\mathrm{kg}$ ) azithromycin compared with 10-day amoxicillin/clavulanate for the treatment of uncomplicated acute otitis media: a double-blind, placebo-controlled, randomized clinical trial. Curr Ther Res Clin Exp 64: 30-42. [Crossref]

21. Morris PS, Gadil G, McCallum GB, Wilson CA, Smith-Vaughan HC, et al. (2010) Single-dose azithromycin versus seven days of amoxycillin in the treatment of acute otitis media in Aboriginal children (AATAAC): a double blind, randomised controlled trial. Med J Aust 192: 24-29. [Crossref]

22. Arguedas A, Emparanza P, Schwartz RH, Soley C, Guevara S, et al. (2005) A randomized, multicenter, double blind, double dummy trial of single dose azithromycin versus high dose amoxicillin for treatment of uncomplicated acute otitis media. Pediatr Infect Dis J 24: 153-161. [Crossref]

23. Principi N (1995) Multicentre comparative study of the efficacy and safety of azithromycin compared with amoxicillin/clavulanic acid in the treatment of paediatric patients with otitis media. Eur J Clin Microbiol Infect Dis 14: 669-676. [Crossref]

Copyright: (C2021 Pinto JA. This is an open-access article distributed under the terms of the Creative Commons Attribution License, which permits unrestricted use, distribution, and reproduction in any medium, provided the original author and source are credited. 